\title{
miRNA-34b as a tumor suppressor in estrogen- dependent growth of breast cancer cells
}

\author{
Yee-Ming Lee ${ }^{1,2}$, Jen-Yi Lee ${ }^{1,2}$, Chao-Chi Ho ${ }^{3}$, Qi-Sheng Hong ${ }^{4}$, Sung-Liang Yu ${ }^{4}$ Chii-Ruey Tzeng ${ }^{5}$, Pan-Chyr Yang ${ }^{3}$ \\ and Huei-Wen Chen $^{2^{*}}$
}

\begin{abstract}
Introduction: Estrogen is involved in several physiological and pathological processes through estrogen receptor (ER)-mediated transcriptional gene regulation. miRNAs (miRs), which are noncoding RNA genes, may respond to estrogen and serve as posttranscriptional regulators in tumorigenic progression, especially in breast cancer; however, only limited information about this possibility is available. In the present study, we identified the estrogen-regulated miR-34b and investigated its functional role in breast cancer progression.

Methods: Estrogen-regulated miRNAs were identified by using a TaqMan low density array. Our in vivo Tet-On system orthotopic model revealed the tumor-suppressive ability of miR-34b. Luciferase reporter assays and chromatin immunoprecipitation assay demonstrated miR-34b were regulated by p53-ER interaction.
\end{abstract}

Results: In this study, we identified one such estrogen downregulated miRNA, miR-34b, as an oncosuppressor that targets cyclin D1 and Jagged-1 (JAG1) in an ER+/wild-type p53 breast cancer cell line (MCF-7), as well as in ovarian and endometrial cells, but not in ER-negative or mutant p53 breast cancer cell lines (T47D, MBA-MB-361 and MDAMB-435). There is a negative association between $E R \alpha$ and miR-34b expression levels in ER+ breast cancer patients. Tet-On induction of miR-34b can cause inhibition of tumor growth and cell proliferation. Also, the overexpression of miR-34b inhibited ER+ breast tumor growth in an orthotopic mammary fat pad xenograft mouse model. Further validation indicated that estrogen's inhibition of miR-34b expression was mediated by interactions between ER $\alpha$ and p53, not by DNA methylation regulation. The xenoestrogens diethylstilbestrol and zeranol also showed similar estrogenic effects by inhibiting miR-34b expression and by restoring the protein levels of the miR-34b targets cyclin D1 and JAG1 in MCF-7 cells.

Conclusions: These findings reveal that miR-34b is an oncosuppressor miRNA requiring both ER+ and wild-type p53 phenotypes in breast cancer cells. These results improve our ability to develop new therapeutic strategies to target the complex estrogenic pathway in human breast cancer progression through miRNA regulation.

\section{Introduction}

Breast cancer is the most frequently occurring cancer in women [1], and the majority of the cases (about 70\%) are estrogen receptor (ER)-positive (ER+) [2-4]. Activated, functional ER can stimulate tumor growth and cell proliferation; therefore, it has been postulated that in most ER+ breast tumors, ER is the driving force underlying tumorigenesis, rendering it a principal target for treatment $[5,6]$. The agents that antagonize estrogenic action (for example, tamoxifen (TAM) and other

\footnotetext{
* Correspondence: shwchen@ntu.edu.tw

${ }^{2}$ Graduate Institute of Toxicology, College of Medicine, National Taiwan

University, No. 1, Sec. 1, Ren-Ai Road, Taipei, 100, Taiwan

Full list of author information is available at the end of the article
}

selective estrogen receptor modulators (SERMs)) are used clinically to treat ER+ breast cancer patients. However, for some ER+ patients, these drugs are not effective for long-term use, and, in addition, many are not responsive to hormone therapy at all [7]. Therefore, the challenge is to further clarify the ER signaling pathway to identify other therapeutic targets and to develop new predictive biomarkers for better treatments.

ER signaling is complicated. ER is known to associate with numerous cofactors that act at multiple levels, including transcription, translation and even posttranslation. The classical estrogen pathway is the direct binding of estrogen-responsive elements by ligand-activated ER to regulate gene expression. Estrogen may also act as a 
coactivator of other transcription factors to turn on oncogenes in breast cancer in the nonclassical pathway [8-10]. Furthermore, estrogen can stimulate rapid, extranuclear (nongenomic) signaling events, such as the activation of the Src/Ras/Erk signaling pathway. Although the mechanisms of estrogen signaling in breast cancer have been extensively studied, there are still elusive interactions to be elucidated.

miRNAs (miRs) are an evolutionarily conserved class of small, noncoding RNAs of approximately 22 nucleotides that decrease gene expression posttranscriptionally by complementary binding to the mRNA 3'UTR in a sequence-specific manner, resulting in cleavage or translational repression of the target mRNA [11]. Many miRNAs have been correlated with various kinds of cancers and function as oncogenes or tumor suppressor genes [12]. Recently, the miRNA expression profile for breast cancer has been reported in a study in which comparisons between normal and tumorous breast tissues revealed that miR-10b, miR-125b and miR-145 were downregulated and that miR-21 and miR-155 were upregulated [13]. Furthermore, studies comparing miRNA profiles in breast cancer with different ER/progesterone (PR)/HER2 levels showed that specific miRNA expression levels could be correlated to different ER/PR status (miR-142-5p, miR-200a, miR-205 and miR-25) and HER2 status (let-7f, let-7g, miR-107, miR-10b, miR126, miR-154 and miR-195) [14]. These studies suggest that miRNAs could play pivotal roles in the pathological and molecular functions in the tumorigenesis of breast cancer. Hormone-regulated miRNAs might be potential therapeutic targets or might serve as prognostic markers for hormone-dependent tumors. However, few studied have focused on hormone regulation of miRNAs in breast cancer.

To identify estrogen-regulated miRNAs in breast cancer, we examined the miRNA profile of the ER+ breast cancer cell line MCF-7 with and without estrogen treatment using a real-time, quantitative PCR (qPCR)-based TaqMan low density array (TLDA; Applied Biosystems, Foster City, CA, USA). One of the estrogen-regulated miRNAs, miR-34b, has been identified and has been functionally validated as a tumor suppressor miRNA downregulated by estrogen. We demonstrate herein that estrogen regulates the promoter activity of miR-34b gene through the interaction between ER and p53. Previous studies showed that miR-34b has important functions in cell proliferation and apoptosis and also serves as a direct transcriptional target of p53 [15-17]. Herein, on the basis of clinical and in vivo animal models, we show that miR-34b may play a role in controlling the growth of ER+ breast cancer. The evidence we present suggests that miR-34b is a crucial factor in ER+ breast cancer tumorigenesis and may serve as a target for
miRNA-based breast cancer therapy or as a miRNAbased prognostic marker, and we provide new insights into breast cancer treatments.

\section{Materials and methods}

Patient tissue specimens

Specimens from 47 breast cancer patients were used for miRNA analysis. The study was approved by the Institutional Review Board of the National Taiwan University Hospital, Taipei, Taiwan. Written informed consent was obtained from all patients. Frozen sections of breast cancer tissue were obtained when patients underwent surgical resection of breast tumors at the National Taiwan University Hospital between December 2003 and December 2006. The 47 clinical samples were grouped according to pathological classification, which included the ER, PR and HER2 status. Of these specimens, 26 samples were ER+ and 21 samples were ER-negative (ER-). The clinical characteristics of the breast cancer patients are listed in Table 1. None of these patients had received adjuvant chemotherapy.

\section{Cells and treatments}

MCF-7 cells were purchased from America Type Culture Collection (ATCC; Manassas, VA, USA). The cells were maintained in $10 \%$ fetal bovine serum (FBS) as prescribed. MDA-MB-361, MDA-MB-435, T47D and OVCAR4 cells were purchased from among the NCI-60 cell lines (Developmental Therapeutics Program, National Cancer Institute, Frederick, MD, USA) and cultured in RPMI 1640 with 10\% FBS as prescribed. 293T cells were purchased from ATCC and maintained in $10 \%$ FBS as prescribed. The ligands $17 \beta$-estradiol (E2), 4-hydroxytamoxifen (4-OHT), diethylstilbestrol (DES) and zeranol (ZEA) were purchased from Sigma-Aldrich (St Louis, MO, USA). Before MCF-7 cells were treated with ligands, the medium was replaced with phenol red free $\alpha$-MEM (Life Technologies, Rockville, MD, USA) containing $10 \%$ dextran charcoal-stripped FBS (Thermo

\section{Table 1 Clinical characteristics of breast cancer patients}

\begin{tabular}{|c|c|c|c|}
\hline Patient demographics & ER+ & ER- & $\begin{array}{c}P \text { - } \\
\text { value }\end{array}$ \\
\hline Patients, $n$ (\%) & $26(55.32 \%)$ & $21(44.68 \%)$ & \\
\hline Mean age \pm SD (years) & $53.44 \pm 13.79$ & $54.95 \pm 10.13$ & $0.68^{a}$ \\
\hline \multicolumn{4}{|l|}{ Tumor stage, $n(\%)$} \\
\hline Stage I & $11(42.31 \%)$ & $8(38.10 \%)$ & $0.7699^{b}$ \\
\hline Stages II and III & $15(57.69 \%)$ & $13(61.90 \%)$ & \\
\hline \multicolumn{4}{|l|}{ Tumor type, $n$ (\%) } \\
\hline HER2+ & $15(57.69 \%)$ & $12(57.14 \%)$ & $0.9698^{b}$ \\
\hline HER2- & $11(42.31 \%)$ & $9(42.86 \%)$ & \\
\hline $\begin{array}{l}\text { 5-year disease-free survival, } n \\
\text { (\%) }\end{array}$ & $16(61.54 \%)$ & $13(61.90 \%)$ & $0.9795^{b}$ \\
\hline
\end{tabular}


Fisher Scientific Inc, Waltham, MA, USA) for 3 days. Cells were treated with $10 \mathrm{nM} \mathrm{E2,} 100 \mathrm{nM}$ 4-OHT, 10 nM DES or $10 \mathrm{nM}$ ZEA for 24 hours prior to analyses.

\section{Proliferation assay}

A 3-(4,5-dimethylthiozol-2-yl)-2,5-diphenyltetrazolium bromide (MTT) (Sigma-Aldrich) assay was performed to determine cell proliferation. Briefly, MCF-7 cells were plated in 96-well plates at a density of $5 \times 10^{3} /$ well. After 24-hour incubation, cells were serum-starved overnight. The cells were then treated with different concentrations of estrogen for indicated times, then culture medium containing $0.5 \mathrm{mg} / \mathrm{ml}$ MTT solution was added to each well. After 1.5-hour incubation, the medium was removed and dimethyl sulfoxide was added to the wells. The color intensity of solubilized formazan was measured at $570 \mathrm{~nm}$ with an ELISA plate reader (VICTOR X3 Multilabel Plate Reader; PerkinElmer, Waltham, MA, USA).

\section{Anchorage-dependent colony formation assay}

Six-well plates were used for seeding 100 cells in $\alpha$ MEM supplemented with 10\% FCS. E2 and 4-OHT were added to the plate at different concentrations every 2 days. Plates were incubated in a $37^{\circ} \mathrm{C}$ incubator for 2 weeks. The number of colonies was counted after they were stained with $0.05 \%$ crystal violet (Sigma-Aldrich) for 1 hour and washed extensively with PBS.

\section{TaqMan Low Density Array}

The human miRNA TLDA contains eight sample-loading lines, each of which is connected by a microchannel to 48 miniature reaction chambers for a total of 384 wells per card. It contains 365 different human miRNA assays plus two carefully selected small nucleolar RNAs (snRNAs) that function as endogenous controls for data normalization. The human miRNA TLDA was used in conjunction with Multiplex reverse transcriptase (RT; Applied Biosystems) consisting of eight predefined RT primer pools containing up to 48 RT primers each. All 365 miRNA targets were reversetranscribed in eight separate $\mathrm{RT}$ reactions, and each $\mathrm{RT}$ reaction was pipetted into one of the eight filling ports on the TaqMan array. To perform PCRs, we used a 7900HT Fast Real-Time PCR System (Applied Biosystems), and SDS version 2.3 software (Applied Biosystems) was used for comparative differential expression $(\Delta \mathrm{Ct})$ analysis.

\section{Quantitative real-time PCR analysis of miRNA expression} Total RNAs were extracted from cells using TRIzol reagent (Invitrogen/Life Technologies, Carlsbad, CA, USA). miRNAs were quantified using TaqMan miRNA assays (Applied Biosystems). U6B was used for normalization of miRNA expression. The PCR was run in a 7900 HT Fast Real-Time PCR System, and SDS version 2.3 software (Applied Biosystems) was used for comparative $\Delta \mathrm{Ct}$ analysis. Experiments were performed three times in triplicate.

\section{Western blot analysis}

MCF-7 cells were treated with the chemicals described above. Cells were washed twice with ice-cold PBS and collected for protein extraction. Protein was extracted by using mammalian protein extraction reagent (Pierce Biotechnology, Inc, Rockford, IL, USA) containing protease inhibitors (Sigma-Aldrich). SDS-PAGE with 10\% resolving gel was used to separate proteins ( $25 \mathrm{mg} /$ lane). Mouse anti-cyclin D1 mAb (Merck KGaA, Darmstadt, Germany), mouse anti-Jagged-1 (anti-JAG1) mAb (Santa Cruz Biotechnology, Santa Cruz, CA, USA) and mouse anti- $\beta$-actin mAb (Santa Cruz Biotechnology) were all used according to the manufacturer's instructions. Bound antibodies were detected using an enhanced chemiluminescence system (Santa Cruz Biotechnology). Chemiluminescent signals were captured using the Fujifilm LAS-3000 system (Fujifilm, Tokyo, Japan). All experiments were performed at least three times in triplicate.

\section{Vectors and constructs}

We used the pSilencer 4.1-CMV puro vector (Applied Biosystems), the pTRE-Tight vector (631059; Clontech Laboratories, Inc, Mountain View, CA, USA) and the Tet-On vector (Clontech Laboratories, Inc) in the plasmid constructs. A precursor form of miR-34b was inserted into the pSilencer 4.1-CMV puro vector, then subcloned into the pTRE-Tight vector for overexpression. Primer sequences are shown in Additional file 1, Supplementary Table 1.

\section{Stable clone and precursor miRNA transfection}

MCF-7 cells were plated in six-well plates at a density of $5 \times 10^{5}$ cells per well in Opti-MEM Reduced Serum Medium (Life Technologies) supplemented with $10 \%$ FBS. Lipofectamine 2000 transfection reagent (Invitrogen/Life Technologies) and pTRE-miR-34b and Tet-On plasmids were mixed according to the manufacturer's instructions and added to the cells. After 6 hours of incubation, the medium was changed with fresh $\alpha$ MEM plus 10\% FBS. After cotransfection of the two plasmids, stable clones were selected by addition of neomycin $(1 \mathrm{mg} / \mu \mathrm{l})$. Precursor miRNAs, antagomirs and negative controls (mock transfection) were obtained from Applied Biosystems. For precursor miRNA, cells were transfected with Lipofectamine LTX (Invitrogen/ Life Technologies) with $6 \mathrm{nM}$ precursor miRNA and harvested 48 or 72 hours later. 


\section{Methylation-specific PCR and bisulfate sequencing} Genomic DNA was extracted from MCF-7 cells using the QIAamp DNA Mini Kit (QIAGEN, Valencia, CA, USA). Genomic DNA $(2 \mu \mathrm{g})$ was modified by sodium bisulfite using the EZ DNA Methylation Kit (Zymed Research Corp, Irvine, CA, USA). Methylation-specific PCR (MSP) and bisulfite-sequencing PCR (BSP) analysis were then performed as described previously [18]. Primers for MSP and BSP were designed by using the MethPrimer software program [19]. Primer sequences are shown in Additional file 1, Supplementary Table 1.

\section{Promoter reporter assay}

Upstream regions of miR-34b/c were amplified by PCR and then cloned into the pGEM-T Easy Vector System (Promega, Madison, WI, USA). Each PCR primer carried a 5 ' overhang that contained a HindIII recognition site. After verification of the sequences, miR-34b/c fragments were excised using HindIII and ligated into a pGL3Basic vector (Promega). In addition, oligonucleotide fragments corresponding to p53-responsive elements were synthesized and inserted upstream of the miR-34b/ c promoter in the pGL3-Basic vector. Cells $\left(5 \times 10^{4}\right.$ per well in 24-well plates) were transfected with $100 \mathrm{ng}$ of one of the reporter plasmids using Lipofectamine 2000 reagent (Invitrogen/Life Technologies). For cotransfection of reporter genes with ER expression plasmid, equal numbers of cells were cotransfected with $100 \mathrm{ng}$ of one of the reporter plasmids, $100 \mathrm{ng}$ of pcDNA 3.1-ER (Invitrogen/Life Technologies) or an empty vector. The pGL3-Basic vector without an insert served as the negative control. Luciferase activity was measured 48 hours after transfection using a Dual-Luciferase Reporter Assay System (Promega). Primer sequences are shown in Additional file 1, Supplementary Table 1.

\section{Luciferase reporter assay}

The 3'UTRs of human JAG1 and cyclin D1 were amplified from human genomic DNA and cloned into a pMIR-REPORT miRNA Expression Reporter Vector System (Ambion/Life Technologies) by directional cloning. The resultant plasmid was designated Luc-JAG13'UTR-WT and Luc-CyclinD1-3'UTR-WT. To generate the Luc-JAG1-3'UTR-Mut and Luc-CyclinD1-3'UTRMut construct, seed regions were mutated by removing complementary nucleotides of miR-34b. 293T cells $(3 \times$ $10^{5}$ per well) were cotransfected with a $0.5-\mu \mathrm{g}$ firefly luciferase reporter vector and a $0.05-\mu \mathrm{g}$ control vector containing Renilla luciferase, pRL-SV40 (Promega), using Lipofectamine 2000 reagent (Invitrogen/Life Technologies) in six-well Costar plates (Corning Life Sciences, Lowell, MA, USA). For each well, 200 pM miR-34b precursor molecule (Ambion/Life Technologies) or a negative control (mock) precursor miRNA
(Ambion/Life Technologies) was cotransfected with the reporter constructs. Luciferase assays were performed 24 hours after transfection (Dual-Luciferase Reporter Assay System; Promega). Firefly luciferase activity was normalized to Renilla luciferase activity.

\section{Chromatin immunoprecipitation assay}

The chromatin immunoprecipitation (ChIP) assays were carried out as described previously [20]. Chromatin was immunoprecipitated for 16 hours at $4^{\circ} \mathrm{C}$ using $10 \mu \mathrm{l}$ each of anti-RNA polymerase II, clone CTD4H8 (Millipore, Billerica, MA, USA), normal mouse immunoglobulin G (IgG; Millipore) and anti-ER $\alpha$, clone HC-20 (Santa Cruz Biotechnology). In addition, 1/100 of the solution collected before adding the antibody was used as an internal control for the amount of input DNA. PCR was carried out in a $20-\mu \mathrm{l}$ volume containing $1 / 100$ of the immunoprecipitated DNA, blend Taq polymerase and $5 \mu \mathrm{M}$ of each primer. The PCR protocol entailed initial denaturation for $3 \mathrm{~min}$ utes at $94^{\circ} \mathrm{C}$ and 33 cycles of 20 seconds at $94^{\circ} \mathrm{C}, 30 \mathrm{sec}-$ onds at $59^{\circ} \mathrm{C}$ and 30 seconds at $72^{\circ} \mathrm{C}$, followed by a final extension at $72^{\circ} \mathrm{C}$ for 2 minutes. Primer sequences are shown in Additional file 1, Supplementary Table 1.

\section{Orthotopic mammary fat pad xenograft mouse model}

This study was approved by the Institutional Review Board and the Animal Care and Use Committee at National Taiwan University. The survival rate of transfected MCF-7 cells was determined by counting cell numbers using trypan blue. Transfected MCF-7 cells $\left(1 \times 10^{6}\right.$ live cells in $100 \mu \mathrm{l}$ Hank's balanced salt solution) were injected into the mammary fat pads of 5-week-old NOD SCID mice (supplied by the animal center at the College of Medicine, National Taiwan University). To determine whether miR$34 \mathrm{~b}$ could reduce orthotopic tumor growth, the mice were randomized into two groups ( $n=10$ for each group): (1) miR-34b Tet-On overexpression stable clone without doxycycline (Sigma-Aldrich) or (2) miR-34b Tet-On overexpression clone with doxycycline. Mice were injected with doxycycline $(2 \mathrm{mg} / \mathrm{ml})$ in water $[21,22]$ after tumor size reached $5 \mathrm{~mm}^{3}$. Tumor sizes were monitored every 7 days by using electronic vernier calipers, and the tumor volume ( $V$ ) was calculated by using the formula $V=0.4 \times a b^{2}$, where $a$ and $b$ are the longest and shortest diameters of each tumor, respectively.

\section{Immunohistochemistry}

We performed immunohistochemistry by using $5-\mu \mathrm{m}$ formalin-fixed, paraffin-embedded tissue sections, placing them on silane-coated slides and baking them at $70^{\circ} \mathrm{C}$ overnight. Afterward the slides were deparaffinized, hydrated, placed in $10 \mathrm{mM}$ citrate buffer $(\mathrm{pH} \mathrm{6})$ and microwaved for a total of 20 minutes for antigen retrieval. After cooling, the slides were treated with $3 \% \mathrm{H}_{2} \mathrm{O}_{2}$ 
for 15 minutes. Appropriate blocking (3\% BSA and 0.2\% Triton X-100) for 1 hour and anti-cyclin D1, clone $\mathrm{H}$ 295 (Santa Cruz Biotechnology) rabbit pAb was used. Rabbit IgG (Millipore) was used as a negative control. We used the VECTASTAIN Elite ABC Kit (Vector Laboratories, Burlingame, CA, USA) for detection. Chromagen diaminobenzidine (Vector Laboratories) was used, and sections were counterstained with $\mathrm{H} \& \mathrm{E}$.

\section{Statistical analysis}

All experiments were performed in triplicate and analyzed for significant differences by analysis of variance using Microsoft Excel software (Microsoft Corp, Redmond, WA, USA). $P<0.05$ was considered statistically significant. Where appropriate, the data are presented as means \pm SD.

\section{Results}

\section{Estrogen-regulated miRNA profile in ER+ breast cancer} cells

To investigate whether estrogen regulates miRNA expression, the ER+ human breast cancer cell line MCF-
7 was treated with $10 \mathrm{nM}$ E2 for 24 hours, and changes in the miRNA expression profile were analyzed by performing qPCR-based TLDA miRNA assays. Table 2 lists the 26 miRNAs that were significantly downregulated and the 28 miRNAs that were significantly upregulated (greater than fivefold changes) by E2 treatment of MCF7 cells. Among these estrogen-regulated miRNAs, miR$34 \mathrm{~b}$ has been shown to regulate tumor progression in a variety of cancers [15-17,23-25]. Because E2 markedly decreased miR-34b expression levels (72-fold), miR-34b was chosen for further study.

Negative correlation of miR-34b expression level and ER status in ER+ human breast cancers

We next examined the expression levels of miR-34b in 47 human breast cancer patients (Table 2). We found that the ER+ tissues had lower miR-34b expression levels compared to ER- tissues (ER+: $n=26$ vs ER-: $n=$ 21; $P<0.05$ ) (Figure 1A). Moreover, the correlation between miR-34b and ER expression levels were inversely correlated (Pearson coefficient $=-0.4185, P=$

Table 2 Estrogen-regulated miRNA profiles of ER+ breast cancer cell line MCF-7 using TaqMan Low-Density Array

\begin{tabular}{|c|c|c|c|c|c|}
\hline \multicolumn{3}{|c|}{ Downregulated miRNAs } & \multirow[b]{2}{*}{ miRNAs } & \multicolumn{2}{|c|}{ Upregulated miRNAs } \\
\hline miRNAs & Fold change & $P$-value & & Fold change & $P$-value \\
\hline miR-509 & -119.389 & $<0.001$ & miR-189 & 5.024565 & 0.002 \\
\hline miR-376a & -102.459 & $<0.001$ & miR-326 & 5.52856 & $<0.001$ \\
\hline miR-629 & -91.9202 & $<0.001$ & miR-520c & 5.619023 & $<0.001$ \\
\hline miR-34b & -71.9166 & $<0.001$ & miR-520b & 5.787208 & $<0.001$ \\
\hline miR-519d & -63.3272 & $<0.001$ & miR-329 & 6.293726 & $<0.001$ \\
\hline miR-33 & -41.4439 & $<0.001$ & miR-17-3p & 7.373741 & $<0.001$ \\
\hline miR-515-5p & -40.7382 & $<0.001$ & miR-369-3p & 8.591994 & $<0.001$ \\
\hline miR-624 & -38.3289 & $<0.001$ & $\operatorname{miR}-519 c$ & 8.613923 & $<0.001$ \\
\hline $\operatorname{miR}-34 \mathrm{c}$ & -37.07 & $<0.001$ & miR-524 & 11.21323 & $<0.001$ \\
\hline miR-551b & -33.1565 & $<0.001$ & miR-576 & 13.31873 & $<0.001$ \\
\hline miR-564 & -27.6564 & $<0.001$ & miR-653 & 13.9337 & $<0.001$ \\
\hline miR-449 & -25.5663 & $<0.001$ & miR-383 & 15.40733 & 0.004 \\
\hline miR-10b & -22.5561 & $<0.001$ & miR-627 & 15.45773 & $<0.001$ \\
\hline miR-518e & -22.0561 & $<0.001$ & miR-105 & 16.18497 & 0.001 \\
\hline miR-139 & -21.8713 & $<0.001$ & miR-616 & 20.96113 & 0.032 \\
\hline miR-520h & -18.821 & $<0.001$ & miR-422b & 24.21192 & 0.018 \\
\hline miR-453 & -17.2921 & $<0.001$ & miR-452 & 28.38138 & $<0.001$ \\
\hline miR-526b & -10.5159 & 0.014 & miR-380-5p & 33.71417 & 0.007 \\
\hline miR-371 & -9.59159 & $<0.001$ & miR-548b & 42.83806 & $<0.001$ \\
\hline miR-656 & -8.11175 & 0.001 & miR-521 & 44.27376 & 0.005 \\
\hline miR-124a & -6.73618 & $<0.001$ & miR-579 & 45.54916 & $<0.001$ \\
\hline miR-518f & -5.80659 & 0.002 & miR-142-5p & 51.74748 & $<0.001$ \\
\hline miR-135a & -5.40944 & $<0.001$ & miR-519e & 53.65128 & $<0.001$ \\
\hline \multirow[t]{3}{*}{ miR-485-5p } & -5.01188 & 0.003 & miR-185 & 55.94657 & $<0.001$ \\
\hline & & & miR-493 & 92.40058 & $<0.001$ \\
\hline & & & miR-515-3p & 97.85771 & $<0.001$ \\
\hline
\end{tabular}

$E R=$ estrogen receptor. The expression profiles of miRNAs which have at least fivefold changes in expression. We used U6B expression as the internal control to normalize expression levels between the two groups. Experiments were repeated in triplicates. Relative expression $=2{ }^{\wedge}$-(with $10 \mathrm{nM}$ estradiol/without estradiol) 

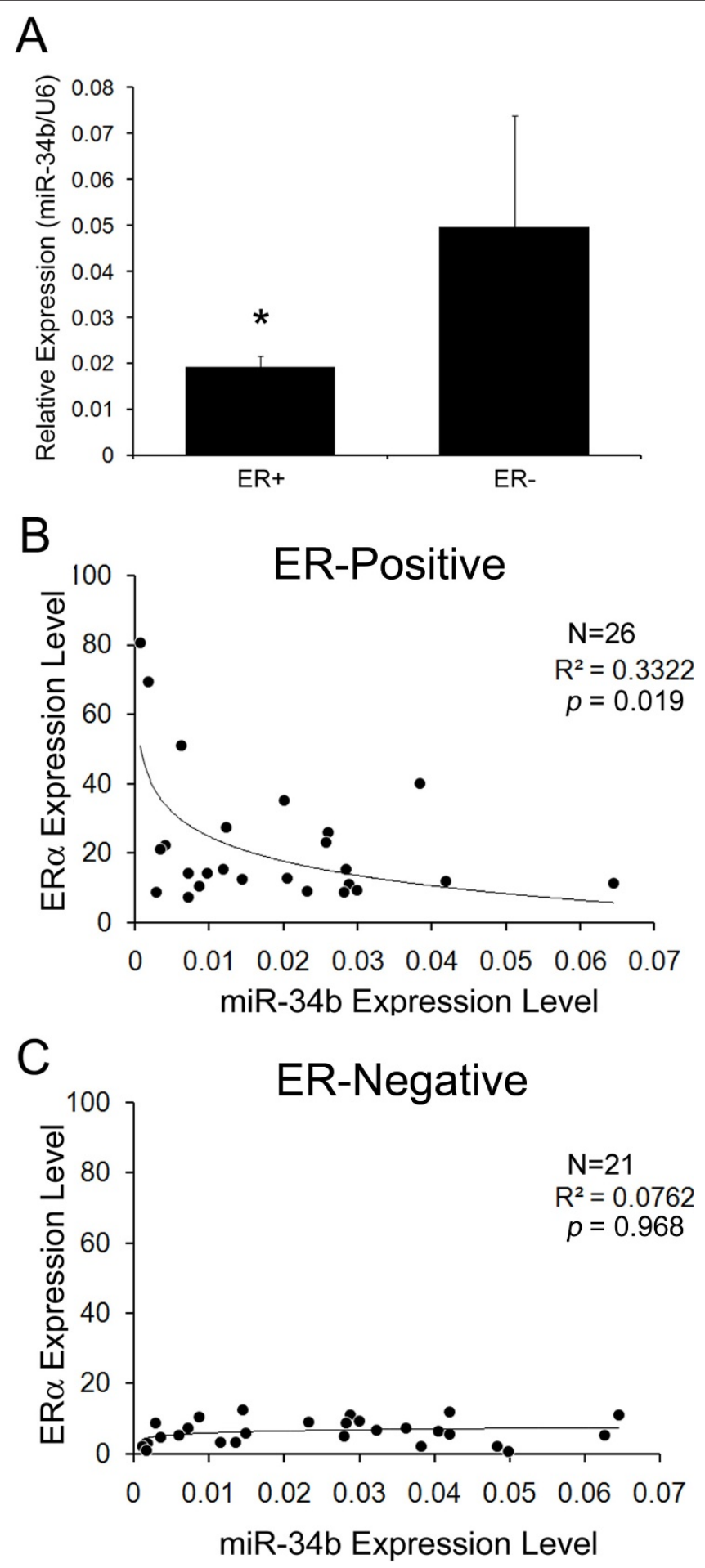

Figure 1 Negative correlation of miRNA (miR)-34b expression level and estrogen receptor (ER) status in ER+ human breast cancers. (A) miR-34b expression in human breast cancer tissue. miR-34b expression levels were analyzed by quantitative PCR (qPCR) (ER+, $n=26$; ER-, $n=$ 21). The results are normalized to internal U6 snRNA expression. (B) Correlation analysis of ER $\alpha$ and miR-34b in ER+ human breast cancer tissues. $P=0.019$. (C) Correlation analysis of ER $\alpha$ and miR-34b in ER- human breast cancer tissues. $P=0.968$. For both parts (B) and (C), ER $\alpha$ mRNA expression levels were analyzed performing SYBR Green $\mathrm{QPCR}$ for each tissue sample. Data represent means \pm SD of triplicate experiments $\left({ }^{*} P<\right.$ 0.05). The results are normalized to internal TaqMan Low-Density Array expression. 
0.0019) for ER+ patients (Figure 1B). However, the correlation of miR-34b and ER showed no significance for ER-patients (Pearson coefficient $=0.009, P=0.9679$ ) (Figure $1 \mathrm{C}$ ). These data suggest that miR-34b expression is closely linked to ER $\alpha$ expression levels in ER+ human breast tumors involved in the complexity of in vivo systems.

\section{Estradiol increased anchorage-dependent colony formation and repressed miR-34b expression in MCF-7 cells}

To verify that miR-34b expression is linked to tumor growth, MCF-7 cells were treated with different concentrations of E2 (0.1, 1.0, 10 and $100 \mathrm{nM})$, and cell proliferation rates were determined. E2 increased anchoragedependent growth in a concentration-dependent manner (Figure 2A), but the expression levels of miR-34b decreased concentration-dependently. E2 (10 nM) treatment reduced miR-34b expression by $88 \%$ in MCF- 7 cells (Figure 2B). The inhibitory effect of estrogen on miR-34b expression was apparent within 2 hours and was sustained for at least 24 hours in MCF-7 cells (Figure $2 \mathrm{~B}$ ). Transfection of precursor miR-34b or antagomir-34b also showed significant decreases or increases in cell proliferation (Figure $3 \mathrm{~A}$ ). These data suggest that miR-34b may serve as a tumor suppressor that regulates tumor progression, as has been reported in a variety of cancers [15-17,23-25].

miR-34b suppressed cell proliferation by direct regulation of Jagged-1 and cyclin D1

Previous studies have shown that high expression of cyclin D1 and Jagged-1 correlate with poor prognosis in breast cancer [26-28]. According to miRNA target gene prediction software, including PicTar, miRanda and miRNAMap, miR-34 could target key regulators of cell proliferation, including cyclin D1 and JAG1 (Figure 3B). To investigate the possible link between miR-34b and
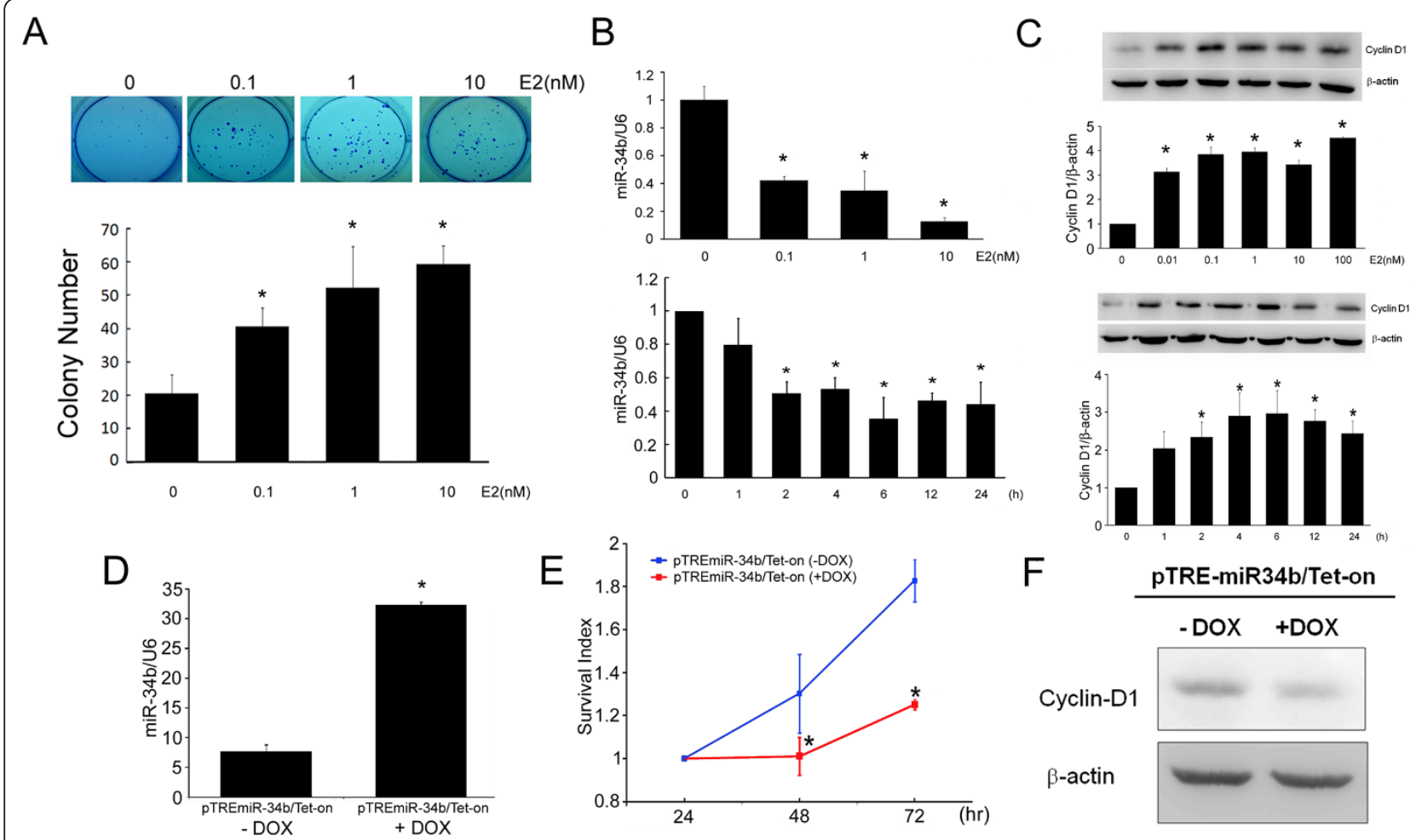

Figure 2 Estradiol (E2) increased anchorage-dependent colony formation and repressed miRNA (miR)-34b expression. (A) Anchoragedependent colony formation assay results. MCF-7 cells were seeded into six-well plates and treated with different concentrations of E2 (0 to 10 nM) for 14 days. Colonies were fixed and stained with crystal violet dye. Representative results are shown in the upper panel. The number of colonies are shown in the bottom panel $(n=3)$. (B) miR-34b expression of MCF-7 cells treated with E2 $(10 \mathrm{nM})$ for different time periods $(n=3)$ or with different concentrations of E2 for 24 hours $(n=3)$. The results were normalized to internal U6 snRNA expression. (C) Western blots of cyclin D1 in MCF-7 cells treated with E2 (10 nM) for different time periods $(n=3)$ or with different concentrations of E2 for 24 hours $(n=3)$. $\beta$ actin was probed as an internal control. The results are expressed as means \pm SD. ${ }^{*} P<0.05$. (D) Stable clones of pTRE-miR-34b/Tet-On were induced by doxycycline (DOX) $(2 \mu \mathrm{M})$ for 48 hours, and miR-34b expression was analyzed by performing quantitative PCR. (E) Cell viability of pTRE-miR-34b/Tet-On in the presence or absence of DOX $(2 \mu \mathrm{g} / \mathrm{ml})$ was detected by using 3-(4,5-dimethylthiozol-2-yl)-2,5-diphenyltetrazolium bromide $(n=3)$. (F) Western blot showing cyclin D1 after miR-34b induction. $\beta$-actin was probed as an internal control. 


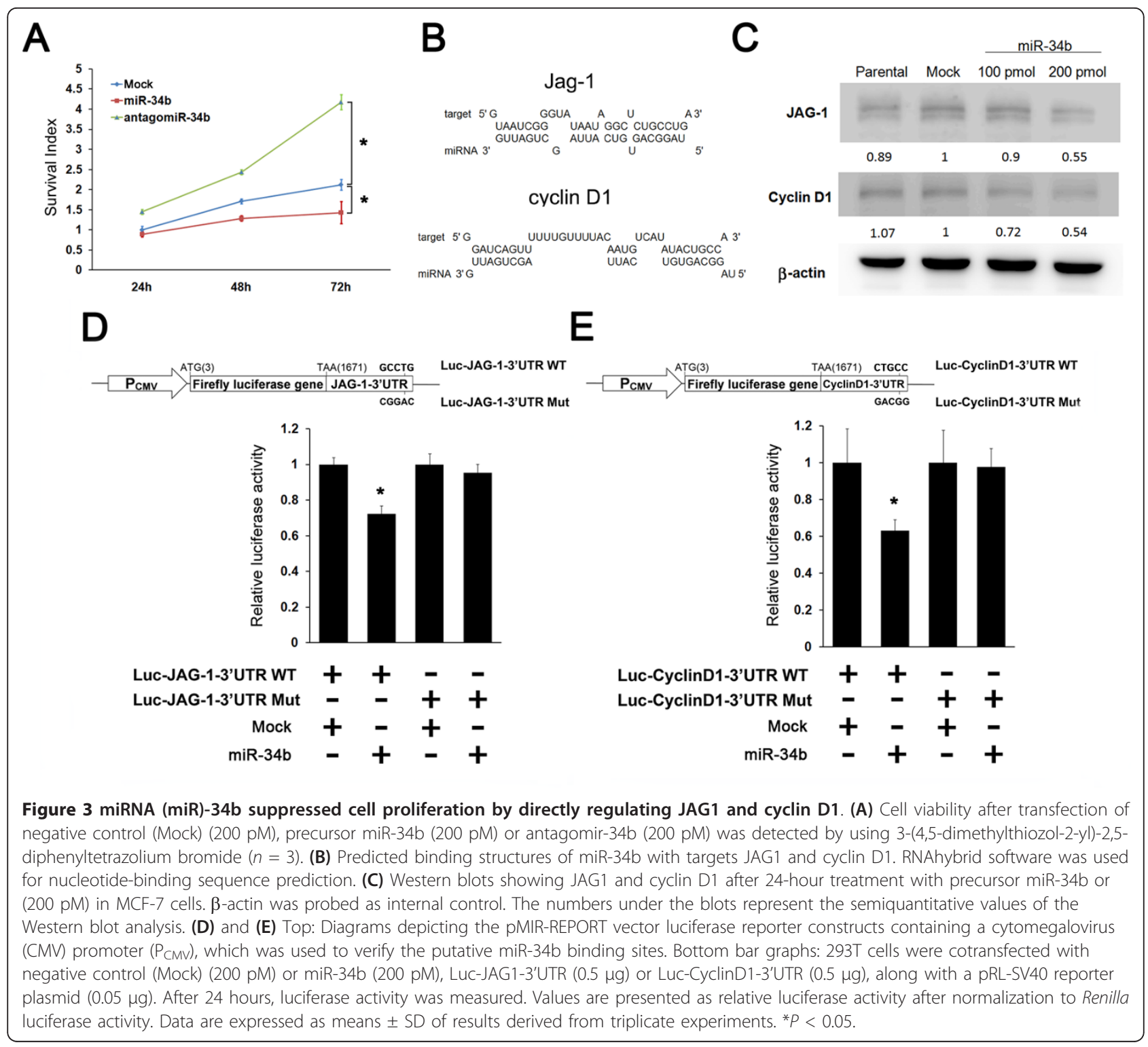

these possible downstream targets, the protein expression levels of cyclin D1 and JAG1 were examined. As shown in Figure 2C, both cyclin D1 and JAG1 were upregulated by treatment with E2 in a concentrationand time-dependent manner. Moreover, overexpression of precursor miR-34b leads to downregulation of JAG1 and cyclin D1 (Figure 3C).

To further confirm the interaction between miR-34b and its putative target genes, we cloned the JAG1 and cyclin D1 3'UTR sequence and inserted it downstream of the firefly luciferase coding region of the pMIRREPORT vector (Figures 3D and 3E). Mutants with the putative binding sites were prepared as described above (see Materials and methods). Our results show that the luciferase activity of the wild-type JAG1 and cyclin D1
3'UTR construct was significantly inhibited after the introduction of miR-34b into 293T cells, but not by the negative control. Mutations of the 3'UTR-binding sites completely abolished the ability of miR-34b to regulate luciferase expression (Figures 3D and 3E). These results demonstrate that JAG1 and cyclin D1 are potential targets of miR-34b. Furthermore, these data suggest that miR-34b may suppress tumor growth through the suppression of cyclin D1 and JAG1 expression.

miR-34b inhibited tumor growth in mouse mammary fat pads xenografted with MCF-7 pTRE-miR-34b/Tet-On stable clones

Since we observed that miR-34b was downregulated in ER+ breast cancer cells (MCF-7 cells), we speculated 
that overexpression of miR-34b might inhibit cell proliferation. To test this hypothesis, we established a miR34b Tet-On overexpression system. In this system, miR$34 \mathrm{~b}$ is conditionally turned on by doxycycline treatment (Figure 2D). Addition of doxycycline significantly decreased cell proliferation (Figure 2E) and cyclin D1 expression (Figure 2F) in MCF-7/miR-34b Tet-On stable clones. Doxycycline did not exert significant effects on cell growth and cyclin D expression in parental and mock transfection of MCF-7 cells (Additional file 2, Figure S1). To test whether miR-34b suppresses tumor growth in vivo, $1 \times 10^{6} \mathrm{MCF}-7 / \mathrm{miR}-34 \mathrm{~b}$ Tet-On stable clones were injected into the mammary fat pads of female NOD SCID mice. Tumor size increased significantly with time. Doxycycline was applied to induce miR-34b expression after tumor size reached $5 \mathrm{~mm}^{3}$. Seven days after induction, the induced miR-34b group showed significant reduction in tumor size compared to the control group $(P<0.05)$ (Figure $4 \mathrm{~A})$. After 28 days, the mice were killed and the tumor volumes were compared. As shown in Figure 4B, the tumor volumes in the induced miR-34b group were significantly lower than in the control group $(P<0.01)$. H \& E staining of the fat pads confirmed that miR-34b induction led to a decrease in tumor size (Figure $4 \mathrm{C}$ ). The miR-34b expression level in Tet-On group was increased 2.76fold compared to the noninduced miR-34b group (Figure 4D). In agreement with these findings, the expression levels of cyclin D1 were significantly reduced in the doxycycline induced group as shown by immunohistochemical staining (Figure 4E).

\section{p53-dependent regulation of miR-34b expression by estradiol}

To investigate how E2 regulates miR-34b, we screened the miR-34b promoter for the presence of ER-responsive elements. However, we could not find any possible binding sites of ER in the miR-34b promoter. This result showed that E2 regulation of miR-34b does not occur through classical ER signaling. Recent studies showed that $\mathrm{p} 53$ could bind to $\mathrm{miR}-34 \mathrm{~b} / \mathrm{c}$ and regulate its expression [16]. Furthermore, the interaction between p53 and ER at the promoter site plays a pivotal role in the regulation of miR-34b expression [29-31].

We first demonstrated that miR-34b promoter activity was significantly inhibited by $10 \mathrm{nM}$ E2 treatment of 293 T cells cotransfected with ER (Figure 5A). In additional experiments, we used breast cancer cell lines bearing different p53 and ER status (MCF-7, T47D and MDA-MB-435). Only cells expressing both wild-type



Figure 4 miRNA (miR)-34b inhibited tumor growth in mouse mammary fat pads xenografted with MCF-7 pTRE-miR-34b/Tet-On stable clones. (A) Tumor size was calculated by using the formula $V=0.4 \times a b^{2}$, where $a$ and $b$ are the longest and shortest diameters of each tumor, respectively. Relative tumor size was normalized by the tumor size measured at day $0(n=10)$. Day $7, P=0.05 ;$ day $14, P=0.0079$; day 21, $P=0.0052$; day 28, $P=0.0061$. (B) Left: Photomicrographs of orthotopic tumors excised from mice. Right: Tumor volume of the orthotopic tumor tissues from doxycycline (DOX)-treated mice $(n=10)$. (C) H \& E-stained tumor tissue sections from each group. (D) Quantitative analysis of miR-34b expression in orthotopic tumors $(n=10)$. The results are normalized to internal U6 snRNA expression and represent means \pm SD. ${ }^{*} P$ $<0.05$; ${ }^{* *} P<0.01$. (E) Immunohistochemical staining of proliferation marker cyclin D1 in orthotopic tumor tissues. IgG =immunoglobulin $\mathrm{G}$. Formalin-fixed, paraffin-embedded tissue sections were prepared and stained as indicated. Bar $=200 \mu \mathrm{M}$. 


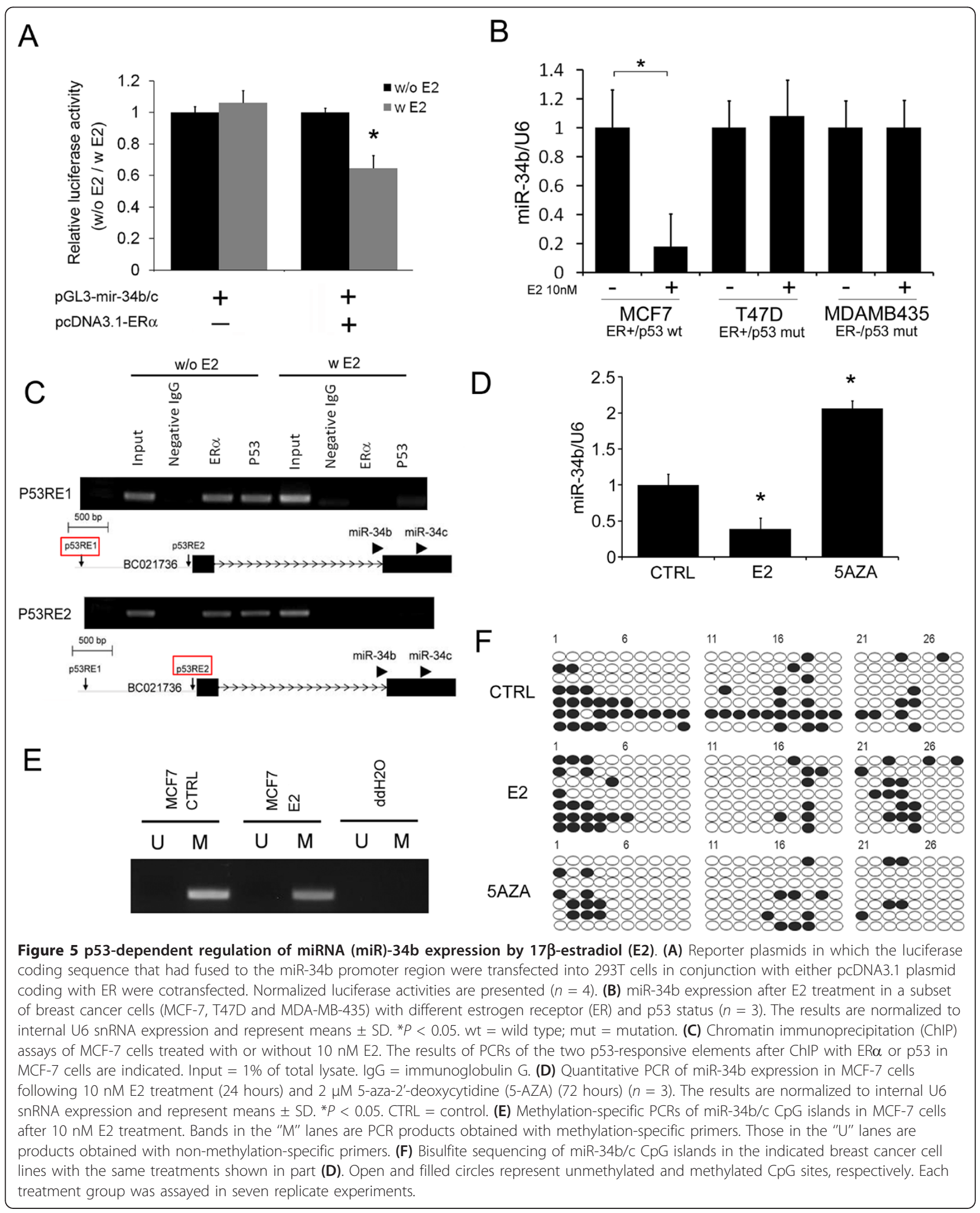


p53 and ER $\alpha$ responded to estrogen repression of miR34b (Figure 5B). These data suggest that both ER and p53 activity are required for E2 to repress miR-34b. We next examined whether both proteins bind to the two p53 binding sites in the miR-34b promoter. ChIP assays confirmed that both p53 and ER bind to the miR-34b/c promoter in the absence of E2 (Figure $5 \mathrm{C}$ ). Binding of p53 to the two p53RE binding sites of the miR-34b promoter region were disrupted by treatment of cells with E2 (Figure 5C). These data support the notion that E2's binding to ER may affect p53's binding to miR-34b promoter through p53-ER interaction.

Previously presented evidence indicated that miR-34b/ c expression may be regulated by DNA methylation [18]. To investigate whether E2 could regulate miR-34b/ c through DNA methylation, we examined the methylation status of the miR-34b/c promoter. Treatment of MCF-7 cells with a DNA methyltransferase inhibitor, 5aza-2'-deoxycytidine (5-aza-dC), increased the expression level of miR-34b (Figure 5D) and reduced the methylation status in the CpG islands of the miR-34b promoter region as demonstrated by MSP and BSP (Figure $5 \mathrm{E}$ ). However, treatment of cells with E2 did not cause significant differences in DNA methylation (Figure $5 \mathrm{~F})$. These data suggest that E2 did not regulate miR34b/c expression through DNA methylation in MCF-7 cells.

\section{Xenoestrogens and tamoxifen regulate miR-34b expression in breast cancer cells}

Some xenoestrogens may play a causative role in breast cancer tumorigenesis [32-35]. To investigate whether xenoestrogen could promote cancer progression by regulating miR-34b (similarly to E2), we examined miR-34b and its downstream target's expression level after xenoestrogen treatment. Our results show that the xenoestrogens DES and ZEA downregulate miR-34b expression in MCF-7 cells (Figure 6A). TAM, a SERM that exhibits antiestrogenic effects in breast tissue, did not affect miR-34b expression levels in MCF-7 cells

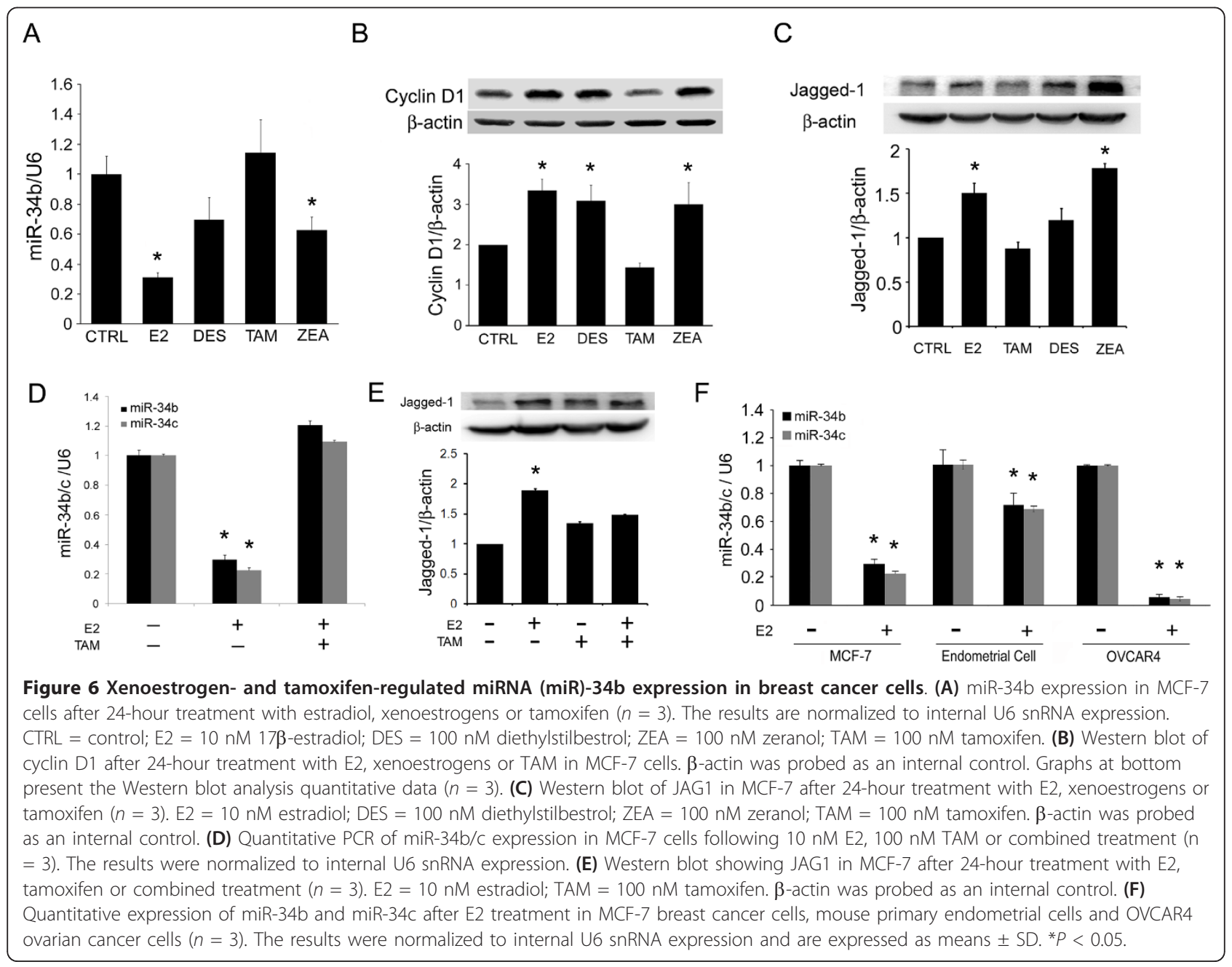


(Figure 6A). In agreement with this finding, the protein levels of cyclin D1 and JAG1 were upregulated by treatment with DES and ZEA, whereas TAM had no significant effect (Figures 6B and 6C). Importantly, combined estrogen and TAM treatment reversed the effect of estrogen on miR-34b (Figures 6D and 6E).

To investigate whether the regulation of $\mathrm{miR}-34 \mathrm{~b}$ expression is tissue-specific, we studied human OVCAR4 ovarian cancer cells and primary culture of mouse endometrial cells. Both of these cells are p53+/+ and E2-responsive. As shown in Figure 6F, E2 downregulated miR-34b/c expression in both OVCAR4 and endometrial cells. These data suggest that the E2 regulation of miR-34b/c maybe a universal event and might also contribute to the proliferation potential in these tissues.

\section{miR-34b/c suppresses cell growth in breast cancer cell lines}

To evaluate this possibility by using $\mathrm{miR}-34 \mathrm{~b} / \mathrm{c}$ as potential therapeutic targets, we obtained four breast cancer cell lines with different ER and p53 status and overexpressed miR-34b/c. Among the four cell lines, MCF-7 expresses ER+ and wild-type p53 (ER+/p53 $\left.{ }^{\mathrm{wt}}\right)$, both T47D and MDA-MB-361 are ER+ and p53-mutant $\left(\mathrm{ER}+/ \mathrm{p} 53^{\mathrm{mut}}\right)$, and MDA-MB-435 is ER- and p53mutant (ER-/p53 $\left.{ }^{\mathrm{mut}}\right)$. As shown in Figure 7, despite the different status of ER and p53, all four cell lines showed a significant decrease in growth after 48 hours with the expression of $\mathrm{miR}-34 \mathrm{~b} / \mathrm{c}$. This result demonstrates that the induction of miR-34b/c could suppress cell growth and that the effect was not influenced by ER or p53 status.

\section{Discussion}

Hormone-regulated miRNAs may be potential therapeutic targets in hormone-dependent tumors. However, few studies have focused on hormone-regulated miRNA expression in breast cancer. In the present study, we analyzed the estrogen-regulated miRNA expression profile in MCF-7 breast cancer cells. We found a set of 54 miRNAs that could be regulated by E2. Among these estrogen-regulated miRNAs, miR-34b was selected for further investigation because it has been reported to be a tumor suppressor in colorectal cancer [18], prostate cancer [25] and gastric cancer [24]. In this study, we have demonstrated for the first time that miR-34b significantly regulates the growth of ER+ breast cancer cells in vitro. We provide evidence that miR-34b plays a pivotal role in the human breast cancer-expressing ER+ phenotype (Figure 8). By establishing Tet-On-inducible miR-34b expression in MCF-7 cells, we have demonstrated that the induction of miR-34b significantly decreases cell proliferation rate in vitro and greatly

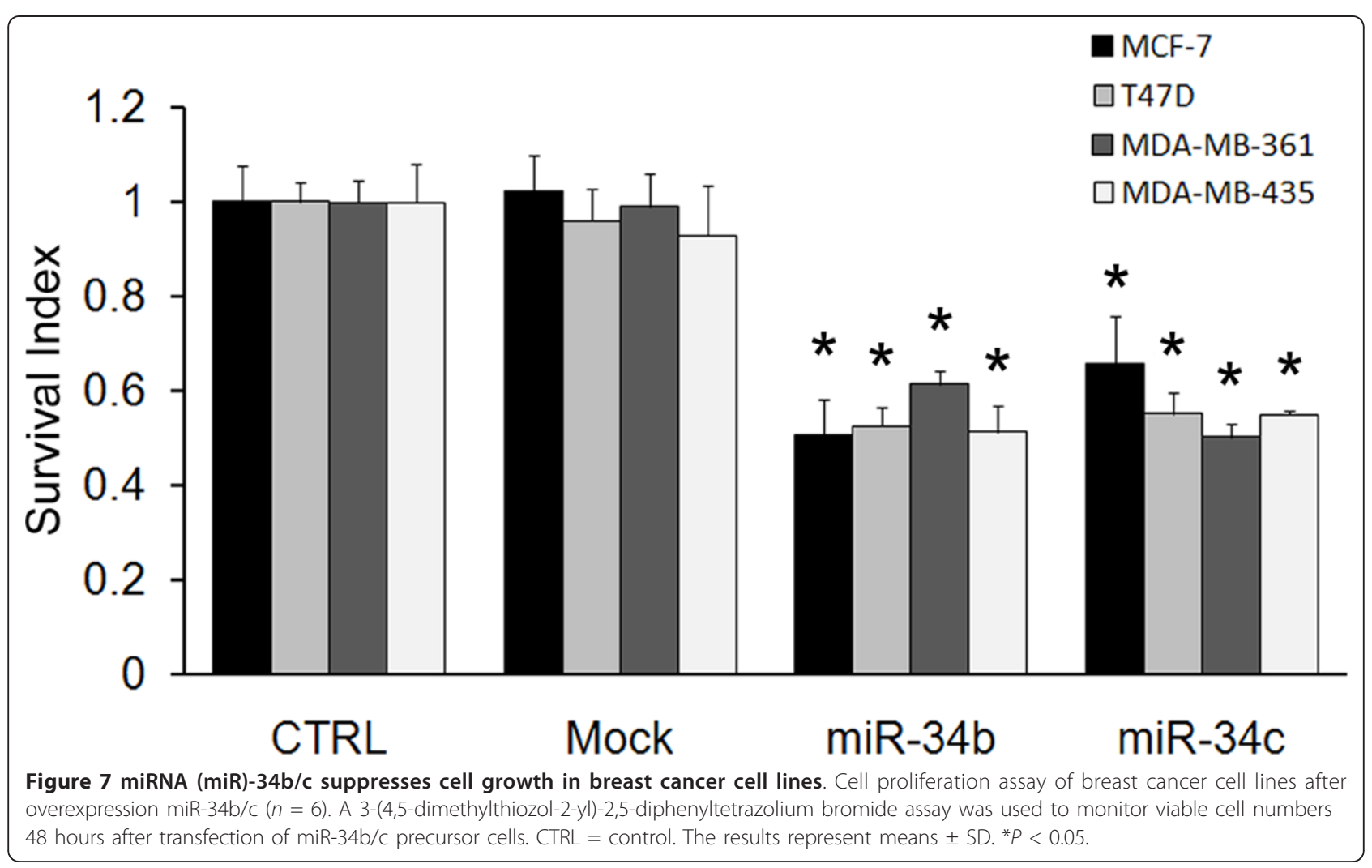




\section{ER(+) Breast Cancer Cell}

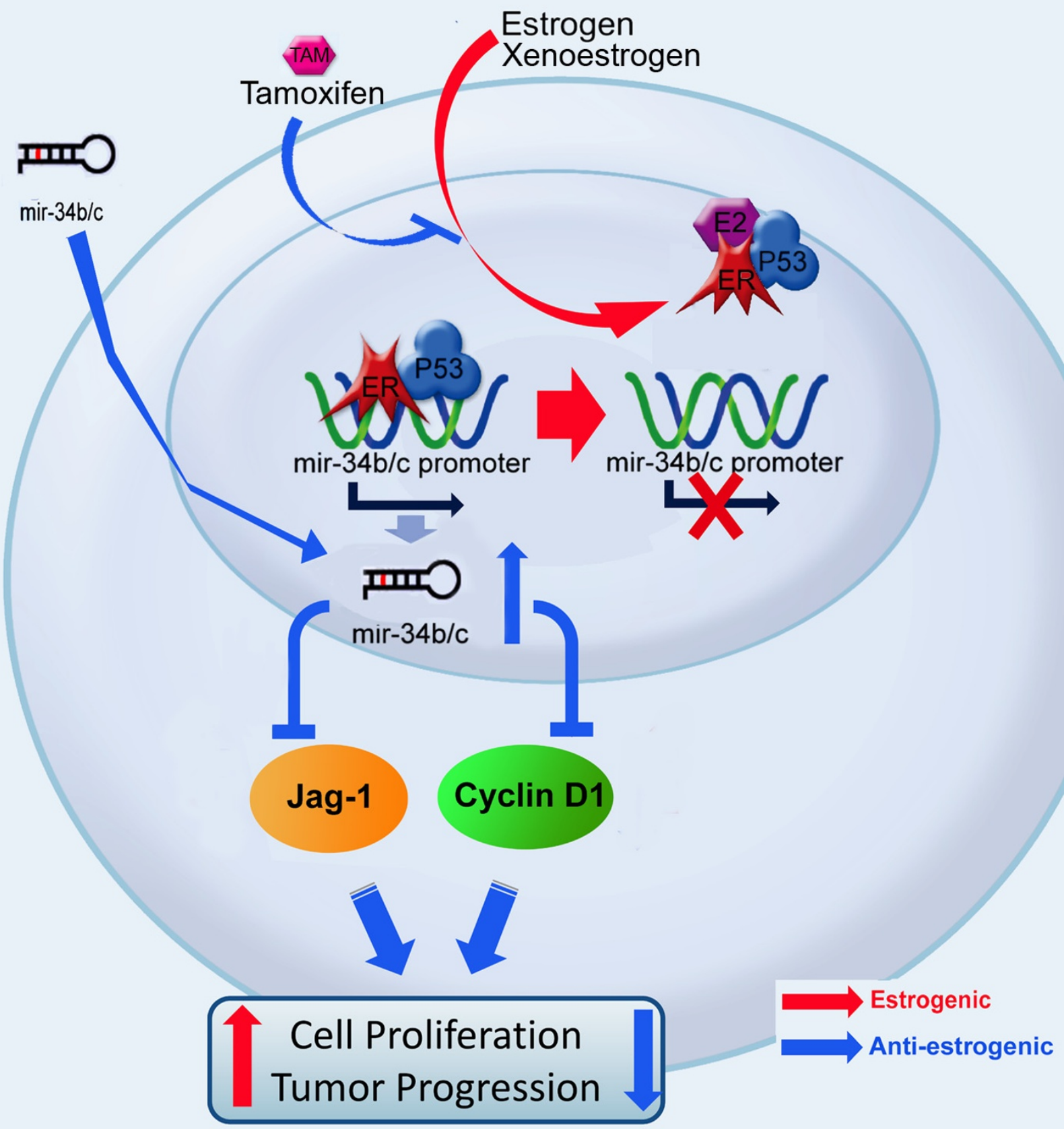

Figure 8 Schematic illustrating estrogen-dependent regulation of miRNA (miR)-34b expression, its target genes and tumor growth. The role of estrogen in the miR-34b-regulating pathway is shown. Under 17ß-estradiol (E2)-free conditions, p53 and estrogen receptor (ER) bind to the miR-34b promoter and activate its transcription. However, in the presence of E2 or xenoestrogens, the activated ER disrupts the binding of the p53-ER complex to the miR-34b promoter region, which subsequently inhibits the tumor-suppressing network and promotes cell proliferation and tumor progression. 
lowers tumor growth in an orthotopic breast cancer model in vivo. We have further demonstrated that the activation of ER by E2 impairs the binding of p53 to the two p53RE regions of the miR-34b promoter leads to repression of miR-34b expression.

In this study, we observed that the expression of miR$34 \mathrm{~b}$ was downregulated by ER signaling, thus we provide evidence of the negative correlation between ER and miR-34b expression levels in patients with ER+ tumors (Figure 1B). The clinical data derived from our experiments show no significant correlation of miR-34b in ER- tumors (Figure 1C). We believe that miR-34b is not likely the only factor involved in tumor progression in ER- breast cancer patients. Since the malignancy in ERbreast cancer patients, and even in patients with triplenegative breast cancer, is quite complicated and since multiple factors might be involved, the malignancy does not rely only on miRNAs. Researchers in recent studies have pointed out that numerous signaling pathways, including the epidermal growth factor receptor, HER2, IGFR and BRCA1/2 pathways [3,36,37], could contribute to the malignancy of ER- breast cancer. On the other hand, ER+ breast cancer cells are not as malignant, and, in addition, the patterns of their malignancy are usually simpler than those of ER-cells, which may be the reason why the miR-34b expression pattern in ER+ cancer patients is more consistent and more important than that in ER- cancer patients.

Previous studies indicated that $\mathrm{miR}-34 \mathrm{~b} / \mathrm{c}$ expression is regulated by $\mathrm{p} 53$, which mediates cell-cycle arrest and promotes apoptosis $[17,38]$. DNA damage or aberrant cell-cycle progression leads to rapid increase of $\mathrm{p} 53$, which in turn may lead to p53-dependent miR34b expression [16]. Overexpression of miR34b decreases the expression of a number of cell-cycle regulatory proteins, including cyclin D1, c-MET and CDK4 $[15,17,23]$, and thus hampers cell-cycle progression $[15,16]$. In this study, we confirmed that p53 participates in miR-34b regulation and leads to cell growth inhibition by targeting cyclin D1. In addition, our computational analysis of miR-34b/c targets using PicTar and miRanda pointed to the Notch ligand JAG1 as another possible target. In agreement with these data, we found that miR-34b inhibited breast cancer cell proliferation by targeting cyclin D1 and JAG1.

Although many reports have described the regulation of the miR-34 family as being mediated mostly through the p53 signaling pathway [15-17,39], miR-34b/c could also be regulated by DNA methylation of CpG islands $[18,40,41]$. Our results show that treatment with 5 -aza$\mathrm{dC}$ (a DNA methyltransferase inhibitor) did increase the expression of $\mathrm{miR}-34 \mathrm{~b} / \mathrm{c}$, but that the methylation status of miR-34b/c promoter was not affected by E2 treatment. Thus it seems unlikely that E2 regulates miR-34b/ c expression through epigenetic regulation. Given that E2 significantly repressed the binding of both p53 and ER to the p53 binding sites in the miR-34b/c promoter, E2's binding to ER may change the conformational structure of ER, which in turn alters p53's binding to the miR34-b/c promoter because of ER-p53 protein-protein interactions.

TAM has been used to treat breast cancer for over 20 years [42]. It has been shown that breast cancer patients bearing $E R \alpha+$ and wild-type p53 phenotypes respond better to TAM therapy $[43,44]$. In contrast, breast cancer patients bearing p53 mutations have a worse prognosis and tend to develop drug resistance earlier [45]. Since the regulation of $\mathrm{miR}-34 \mathrm{~b} / \mathrm{c}$ is dependent on both active $E R \alpha$ and $\mathrm{p} 53$, it provide more hints that ER+ breast cancer patients with wild-type p53 expression might be more responsive than patients with mutant p53 to TAM therapy. On the other hand, TAM is a well-known mixed antagonist/agonist of ER. Depending on cellular context, TAM may act as an intermediate agonist or antagonist [42]. In the endometrium, TAM serves as an agonist to activate gene transcription and thus contributes to the elevated incidence of endometrial tumors in women [46]. We have examined the regulation of miR-34b in both OVCAR4 and endometrial cells. We found that E2 exerts similar miR-34b repression effects in human ovarian cancer cell OVCAR4 cells and mouse primary cultured endometrial cells, suggesting that a general repression mechanism by miR-34b may exist in different tissue types.

Current clinical management of breast cancer relies on various pathological markers to provide suitable therapy. In our study, miR-34b has been showed to inhibit cell growth by targeting cyclin D1 and JAG1, both of which are crucial genes covering various types of breast cancer $[27,47,48]$. Moreover, overexpression of miR-34b leads to inhibition of cell growth in breast cancer cells with different ER and p53 status. These results indicate that miR-34b could be a potential therapeutic target in the treatment of various types of breast cancer.

\section{Conclusions}

In summary, E2 may enhance breast cancer growth by modulating cell-cycle-related genes through the repression of miR-34b. These findings suggest that miR-34b can be considered a new marker for the diagnosis of ER + breast cancer. Furthermore, miR-34b might be used as a therapeutic target for treating breast cancer.

\section{Additional material}

Additional file 1: Supplementary Table 1 Sequences of primers used in this study. Additional experimental data and sequences of primers used in cloning and quantitative RT-PCR. 
Additional file 2: Supplementary Figure 1 Cell viability of Mock and pTRE-miR-34b/Tet-On in the presence or absence of doxycycline (Dox) $(2 \mu \mathrm{g} / \mathrm{ml})$ were detected by performing a 3-(4,5dimethylthiozol-2-yl)-2,5-diphenyltetrazolium bromide (MTT) assay $(n=3)$.

\section{Abbreviations}

a-MEM: minimum essential medium a; BSA: bovine serum albumin; BSP: bisulfate-specific polymerase chain reaction; ChIP: chromatin immunoprecipitation; ER: estrogen receptor; FBS: fetal bovine serum; FCS: fetal calf serum; H \& E: hematoxylin and eosin; HER2: human epidermal growth factor receptor 2; mAb: monoclonal antibody; miRNA: microRNA; MSP: methylation-specific polymerase chain reaction; MTT: 3-(4,5dimethylthiozol-2-yl)-2,5-diphenyltetrazolium bromide; PBS: phosphatebuffered saline; PR: progesterone receptor; RT-PCR: reverse transcriptase polymerase chain reaction; SERM: selective estrogen receptor modulator; snRNA: small nucleolar RNA; UTR: untranslated region.

\section{Acknowledgements}

We gratefully acknowledge the NTU Microarray Core Facility for Genomic Medicine of NRPGM for collaboration and microarray technical assistance. This work was supported by grants from the National Science Council (grant NSC100-2325-B-002-049) and the Department of Health of Taiwan (grant DOH100-TD-B-111-001).

\section{Author details}

'Department and Institute of Pharmacology, College of Medicine, National Yang-Ming University, No. 155, Sec. 2, Linong Street, Taipei, 112, Taiwan. ${ }^{2}$ Graduate Institute of Toxicology, College of Medicine, National Taiwan University, No. 1, Sec. 1, Ren-Ai Road, Taipei, 100, Taiwan. ${ }^{3}$ Department of Internal Medicine, College of Medicine, National Taiwan University, No. 1, Sec. 1, Ren-Ai Rd, Taipei, 100, Taiwan. ${ }^{4}$ Department of Clinical Laboratory Sciences and Medical Biotechnology, College of Medicine, National Taiwan University, No. 1, Sec. 1, Ren-Ai Road, Taipei, 100, Taiwan. ${ }^{5}$ Department of Obstetrics and Gynecology, Taipei Medical University Hospital, No. 252, Wu Hsing Street, Taipei, 110, Taiwan.

\section{Authors' contributions}

YML carried out all the in vitro, in vivo and clinical studies, participated in performing the reporter assay and drafted the manuscript. JYL participated in the design of the study and approved the manuscript. $\mathrm{CCH}$ helped to design, and offered suggestions for, the clinical studies. QSH designed and performed the plasmid construction of the reporter assay. SLY made contributions to the analysis and interpretation of data. CRT made substantial contributions to the conception of the study. PCY contributed intellectual input to the design, implementation and interpretation of the results. HWC conceived the study, participated in its design and coordination, and helped to draft the manuscript. All authors read and approved the final manuscript for publication.

\section{Competing interests}

The authors declare that they have no competing interests.

Received: 21 April 2011 Revised: 6 July 2011

Accepted: 23 November 2011 Published: 23 November 2011

\section{References}

1. Johnston SR: New strategies in estrogen receptor-positive breast cancer. Clin Cancer Res 2010, 16:1979-1987.

2. Ohshiro K, Kumar R: Evolving pathway-driven biomarkers in breast cancer. Expert Opin Investig Drugs 2010, 19(Suppl 1):S51-S56.

3. Alvarez $\mathrm{RH}$, Valero $\mathrm{V}$, Hortobagyi GN: Emerging targeted therapies for breast cancer. J Clin Oncol 2010, 28:3366-3379.

4. Rakha EA, Reis-Filho JS, Ellis IO: Combinatorial biomarker expression in breast cancer. Breast Cancer Res Treat 2010, 120:293-308.

5. Ali S, Coombes RC: Endocrine-responsive breast cancer and strategies for combating resistance. Nat Rev Cancer 2002, 2:101-112
6. Zwart W, Theodorou V, Carroll JS: Estrogen receptor-positive breast cancer: a multidisciplinary challenge. Wiley Interdiscip Rev Syst Biol Med 2011, 3:216-230

7. Rana A, Rangasamy V, Mishra R: How estrogen fuels breast cancer. Future Oncol 2010, 6:1369-1371.

8. Björnström L, Sjöberg M: Mechanisms of estrogen receptor signaling: convergence of genomic and nongenomic actions on target genes. Mol Endocrinol 2005, 19:833-842.

9. Marino M, Galluzzo P, Ascenzi P: Estrogen signaling multiple pathways to impact gene transcription. Curr Genomics 2006, 7:497-508.

10. Green KA, Carroll JS: Oestrogen-receptor-mediated transcription and the influence of co-factors and chromatin state. Nat Rev Cancer 2007, 7:713-722.

11. Meister G, Tuschl T: Mechanisms of gene silencing by double-stranded RNA. Nature 2004, 431:343-349.

12. Esquela-Kerscher A, Slack FJ: Oncomirs: microRNAs with a role in cancer. Nat Rev Cancer 2006, 6:259-269.

13. O'Day E, Lal A: MicroRNAs and their target gene networks in breast cancer. Breast Cancer Res 2010, 12:201.

14. Verghese ET, Hanby AM, Speirs V, Hughes TA: Small is beautiful: microRNAs and breast cancer: where are we now? J Pathol 2008, 215:214-221.

15. He L, He X, Lim LP, de Stanchina E, Xuan Z, Liang Y, Xue W, Zender L, Magnus J, Ridzon D, Jackson AL, Linsley PS, Chen C, Lowe SW, Cleary MA, Hannon GJ: A microRNA component of the p53 tumour suppressor network. Nature 2007, 447:1130-1134.

16. Corney DC, Flesken-Nikitin A, Godwin AK, Wang W, Nikitin AY: MicroRNA$34 b$ and MicroRNA-34c are targets of p53 and cooperate in control of cell proliferation and adhesion-independent growth. Cancer Res 2007, 67:8433-8438.

17. He L, He X, Lowe SW, Hannon GJ: microRNAs join the p53 network: another piece in the tumour-suppression puzzle. Nat Rev Cancer 2007 7:819-822.

18. Toyota M, Suzuki H, Sasaki $Y$, Maruyama R, Imai $K$, Shinomura $Y$, Tokino T: Epigenetic silencing of MicroRNA-34b/c and B-cell translocation gene 4 is associated with $\mathrm{CpG}$ island methylation in colorectal cancer. Cancer Res 2008, 68:4123-4132.

19. Li LC, Dahiya R: MethPrimer: designing primers for methylation PCRs. Bioinformatics 2002, 18:1427-1431.

20. Das PM, Ramachandran K, vanWert J, Singal R: Chromatin immunoprecipitation assay. Biotechniques 2004, 37:961-969.

21. González L, Agulló-Ortuño MT, García-Martínez JM, Calcabrini A, Gamallo C, Palacios J, Aranda A, Martín-Pérez J: Role of c-Src in human MCF7 breast cancer cell tumorigenesis. J Biol Chem 2006, 281:20851-20864.

22. Golubovskaya VM, Zheng M, Zhang L, Li JL, Cance WG: The direct effect of focal adhesion kinase (FAK), dominant-negative FAK, FAK-CD and FAK siRNA on gene expression and human MCF-7 breast cancer cell tumorigenesis. BMC Cancer 2009, 9:280.

23. He X, He L, Hannon GJ: The guardian's little helper: microRNAs in the p53 tumor suppressor network. Cancer Res 2007, 67:11099-11101.

24. Ji Q, Hao X, Meng Y, Zhang M, Desano J, Fan D, Xu L: Restoration of tumor suppressor miR-34 inhibits human p53-mutant gastric cancer tumorspheres. BMC Cancer 2008, 8:266.

25. Rokhlin OW, Scheinker VS, Taghiyev AF, Bumcrot D, Glover RA, Cohen MB: MicroRNA-34 mediates AR-dependent p53-induced apoptosis in prostate cancer. Cancer Biol Ther 2008, 7:1288-1296.

26. Buckley MF, Sweeney KJ, Hamilton JA, Sini RL, Manning DL, Nicholson Rl, deFazio A, Watts CK, Musgrove EA, Sutherland RL: Expression and amplification of cyclin genes in human breast cancer. Oncogene 1993, 8:2127-2133.

27. Reedijk M, Odorcic S, Chang L, Zhang H, Miller N, McCready DR Lockwood G, Egan SE: High-level coexpression of JAG1 and NOTCH1 is observed in human breast cancer and is associated with poor overall survival. Cancer Res 2005, 65:8530-8537.

28. Cohen B, Shimizu M, Izrailit J, Ng NF, Buchman Y, Pan JG, Dering J, Reedijk M: Cyclin D1 is a direct target of JAG1-mediated Notch signaling in breast cancer. Breast Cancer Res Treat 2009, 123:113-124.

29. Liu W, Ip MM, Podgorsak MB, Das GM: Disruption of estrogen receptor ap53 interaction in breast tumors: a novel mechanism underlying the anti-tumor effect of radiation therapy. Breast Cancer Res Treat 2009, 115:43-50 
30. Sayeed A, Konduri SD, Liu W, Bansal S, Li F, Das GM: Estrogen receptor a inhibits p53-mediated transcriptional repression: implications for the regulation of apoptosis. Cancer Res 2007, 67:7746-7755.

31. Liu W, Konduri SD, Bansal S, Nayak BK, Rajasekaran SA, Karuppayil SM, Rajasekaran AK, Das GM: Estrogen receptor-a binds p53 tumor suppressor protein directly and represses its function. J Biol Chem 2006, 281:9837-9840.

32. Li S, Hursting SD, Davis BJ, McLachlan JA, Barrett JC: Environmental exposure, DNA methylation, and gene regulation: lessons from diethylstilbesterol-induced cancers. Ann N Y Acad Sci 2003, 983:161-169.

33. Götz F, Thieme S, Dörner G: Female infertility: effect of perinatal xenoestrogen exposure on reproductive functions in animals and humans. Folia Histochem Cytobiol 2001, 39(Suppl 2):40-43.

34. Liu S, Lin YC: Transformation of MCF-10A human breast epithelial cells by zeranol and estradiol-17ß. Breast J 2004, 10:514-521.

35. Quick EL, Parry EM, Parry JM: Do oestrogens induce chromosome specific aneuploidy in vitro, similar to the pattern of aneuploidy seen in breast cancer? Mutat Res 2008, 651:46-55.

36. Carey L, Winer E, Viale G, Cameron D, Gianni L: Triple-negative breast cancer: disease entity or title of convenience? Nat Rev Clin Oncol 2010, 7:683-692.

37. Burga LN, Hu H, Juvekar A, Tung NM, Troyan SL, Hofstatter EW, Wulf GM: Loss of $B R C A 1$ leads to an increase in epidermal growth factor receptor expression in mammary epithelial cells, and epidermal growth factor receptor inhibition prevents estrogen receptor-negative cancers in BRCA1-mutant mice. Breast Cancer Res 2011, 13:R30.

38. Boominathan $L$ : The guardians of the genome (p53, TA-p73, and TA-p63) are regulators of tumor suppressor miRNAs network. Cancer Metastasis Rev 2010, 29:613-639.

39. Chang TC, Wentzel EA, Kent OA, Ramachandran K, Mullendore M, Lee KH, Feldmann G, Yamakuchi M, Ferlito M, Lowenstein CJ, Arking DE, Beer MA, Maitra A, Mendell JT: Transactivation of miR-34a by p53 broadly influences gene expression and promotes apoptosis. Mol Cell 2007, 26:745-752.

40. Lujambio A, Calin GA, Villanueva A, Ropero S, Sánchez-Céspedes M, Blanco D, Montuenga LM, Rossi S, Nicoloso MS, Faller WJ, Gallagher WM, Eccles SA, Croce CM, Esteller M: A microRNA DNA methylation signature for human cancer metastasis. Proc Natl Acad Sci USA 2008, 105:13556-13561.

41. Lujambio A, Esteller M: CpG island hypermethylation of tumor suppressor microRNAs in human cancer. Cell Cycle 2007, 6:1455-1459.

42. Jordan VC: Chemoprevention of breast cancer with selective oestrogenreceptor modulators. Nat Rev Cancer 2007, 7:46-53.

43. Royds JA, lacopetta B: p53 and disease: when the guardian angel fails. Cell Death Differ 2006, 13:1017-1026.

44. Bergh J, Norberg T, Sjögren S, Lindgren A, Holmberg L: Complete sequencing of the $p 53$ gene provides prognostic information in breast cancer patients, particularly in relation to adjuvant systemic therapy and radiotherapy. Nat Med 1995, 1:1029-1034.

45. Vousden $\mathrm{KH}$, Prives C: p53 and prognosis: new insights and further complexity. Cell 2005, 120:7-10.

46. Brown $\mathrm{K}$ : Is tamoxifen a genotoxic carcinogen in women? Mutagenesis 2009, 24:391-404.

47. Roy PG, Thompson AM: Cyclin D1 and breast cancer. Breast 2006, 15:718-727.

48. Reedijk M, Pinnaduwage D, Dickson BC, Mulligan AM, Zhang H, Bull SB, O'Malley FP, Egan SE, Andrulis IL: JAG1 expression is associated with a basal phenotype and recurrence in lymph node-negative breast cancer. Breast Cancer Res Treat 2008, 111:439-448.

\section{doi:10.1186/bcr3059}

Cite this article as: Lee et al:: miRNA-34b as a tumor suppressor in estrogen-dependent growth of breast cancer cells. Breast Cancer Research 2011 13:R116.

\section{Submit your next manuscript to BioMed Central and take full advantage of:}

- Convenient online submission

- Thorough peer review

- No space constraints or color figure charges

- Immediate publication on acceptance

- Inclusion in PubMed, CAS, Scopus and Google Scholar

- Research which is freely available for redistribution

Submit your manuscript at www.biomedcentral.com/submit
Biomed Central 